\title{
Imaging seismic wave-fields with AlpArray and neighboring European networks
}

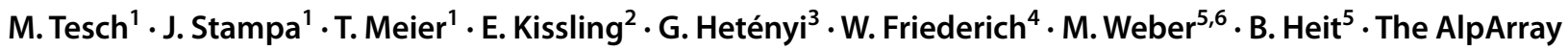 \\ Working Group
}

Received: 1 March 2021 / Accepted: 20 September 2021 / Published online: 25 November 2021

(c) The Author(s) 2021

\begin{abstract}
The AlpArray experiment and the deployment of Swath-D together with the dense permanent network in Italy allow for detailed imaging of the spatio-temporal imaging complexity of seismic wave-fields within the greater Alpine region. The distance of any point within the area to the nearest station is less than $30 \mathrm{~km}$, resulting in an average inter-station distance of about $45 \mathrm{~km}$. With a much denser deployment in a smaller region of the Alps (320 km in length and $140 \mathrm{~km}$ wide), the Swath-D network possesses an average inter-station distance of about $15 \mathrm{~km}$. We show that seismogram sections with a spatial sampling of less than $5 \mathrm{~km}$ can be obtained using recordings of these regional arrays for just a single event. Multiply reflected body waves can be observed for up to $2 \mathrm{~h}$ after source time. In addition, we provide and describe animations of long-period seismic wave-fields using recordings of about 1300-1600 broadband stations for six representative earthquakes. These illustrate the considerable spatio-temporal variability of the wave-field's properties at a high lateral resolution. Within denser station distributions like those provided by Swath-D, even shorter period body and surface wave features can be recovered. The decrease of the horizontal wavelength from $P$ to $S$ to surface waves, deviations from spherically symmetric wavefronts, and the capability to detect multi-orbit arrivals are demonstrated qualitatively by the presented wave-field animations, which are a valuable tool for educational, quality control, and research purposes. We note that the information content of the acquired datasets can only be adequately explored by application of appropriate quantitative methods accounting for the considerable complexity of the seismic wave-fields as revealed by the now available station configuration.
\end{abstract}

Keywords Seismology $\cdot$ Wave-fields $\cdot$ Animations $\cdot$ Alps $\cdot$ AlpArray $\cdot$ Swath-D

The AlpArray Working Group is given in "Acknowledgements" section.

\section{Tesch}

marcel.tesch@ifg.uni-kiel.de

The AlpArray Working Group

http://alparray.ethz.ch/

1 Christian-Albrechts-Universität zu Kiel, Kiel, Germany

2 Eidgenössische Technische Hochschule Zürich, Zurich, Switzerland

3 Université de Lausanne, Lausanne, Switzerland

4 Ruhr-Universität Bochum, Bochum, Germany

5 Deutsches GeoForschungsZentrum Potsdam, Potsdam, Germany

6 Universität Potsdam, Potsdam, Germany

\section{Introduction}

Already in 1889, Rebeur-Paschwitz suggested in the first description of the recording of a teleseismic event (at seismometers in Hamburg and Potsdam) to build a global network of identical stations to monitor the world-wide seismicity (Rebeur-Paschwitz 1889). The ca. 100 Wiechertseismometers deployed world-wide until the 1920s were part of such a network, but it was not until the 1960s that the ca. 120 stations of the World-Wide Standardized Seismograph Network (WWSSN) provided the global infrastructure, technical station capabilities, and data-exchange procedures needed (e.g. Oliver and Murphy 1971) to enabled the construction of the first seismogram sections for the entire earth (Müller and Kind 1976).

The next step in the observation of seismic signals was the installation of seismic arrays like the Yellowknife Seismological Array (YKA) (Muirhead and Datt 1976), a system 
of linked seismometers arranged in a regular geometric pattern (e.g. cross, circle, and rectangle), to increase sensitivity. Arrays with broadband seismometers allowing the study of the full wave spectrum became first operational in 1976 (Buttkus et al. 1986). While modelling of the wave propagation has been performed since the 1960s, the advent of better computing facilities in the 1990s enabled the visualization and analysis of the propagation and interaction of seismic waves inside the earth, even including lateral inhomogeneities at high spatial and temporal resolution (Wysession and Shore 1994; Igel and Weber 1995, 1996).

On the data side, the next big advance was marked by the simultaneous deployment of hundreds of mobile broadband stations like in the USArray (Meltzer et al. 1999) with typical inter-station distances of ca. $70 \mathrm{~km}$ (IRIS Transportable Array 2003), used in a rolling scheme to cover a greater area. This led to the visualization and analysis of waves propagating at the earth's surface as two-dimensional images, in contrast to the classical seismogram analysis (Pollitz 2008). Examples for the deployment of mobile temporary networks in Europe are the IberArray (Díaz et al. 2007), ScanArray (Thybo 2021), SIMBAAD (Paul et al. 2008), EGELADOS (Friederich and Meier 2011), TOR (TOR Working Group et al. 2002), or PASSEQ (Wilde-Piórko 2008).

Following the decades of high-quality active and passive seismological investigations in the Alps, usually along profiles or over subregions of the mountain belt, the European observatory and university research communities joined hands to realize the AlpArray Seismic Network (AASN) within the AlpArray initiative (Hetényi 2018). This major undertaking was only possible through large-scale technical, financial, and organizational coordination: 36 institutions from 11 countries participated in operating the AASN for nearly three years from early 2016 . The network is composed of 628 stations in total: 352 permanent and 276 temporary stations on land, and 30 ocean-bottom seismometers in the Ligurian Sea.

In the planning years of the AASN, the number of existing permanent stations with accessible data increased by $50 \%$. The corresponding plans for the temporary station sites evolved with time, to ultimately leave no point in the Alps and its surroundings (a $250 \mathrm{~km}$ wide region from the foothills) farther than $30 \mathrm{~km}$ away from a broadband station ( $\geq 30 \mathrm{~s}$ upper corner period).

The simultaneous operation of the entire AASN officially started on 1st of January 2016 and lasted for 39 months. Each site on land operated for at least 2 years and the majority did for much longer. The full dataset has been recently opened to the entire AlpArray community and will become publicly available on 1st of April 2022. For further details on the AASN, we refer to Hetényi (2018) and references therein.

The aim of the AlpArray experiment is to image the deep structure of the Alps and to understand the effects of collisional mountain building on a larger scale. The Alps have been the focus of geological research for centuries, with concepts like nappe stacking and subduction first being introduced for the Alpine orogeny (e.g. Price and McClay 1981; Lugeon 1902; Termier 1906; Argand 1916; Faccenna et al. 2001, 2004; Vignaroli et al. 2008, 2009; Handy et al. 2010). To understand the driving forces of mountain building, the slab geometry and deep crustal structure have to be revealed. Because of the small lateral and highly curved geometries found in this region, this remains a challenge. Furthermore, major ambiguities regarding the presence of slab segments, slab gaps, and slab polarity switches might be resolved using advanced seismological imaging techniques taking advantage of the available dense station coverage (AlpArray Science Plan 2013; Hetényi 2018).

To illustrate the potential afforded by data recorded with this modern infrastructure, we present animations of seismic wave-fields propagating across the Greater Alpine area, showing the spatial complexity that is able to be resolved with such a dense network of stations. We show seismogram sections and wave-field animations, including data from the AlpArray Seismic Network (Molinari et al. 2016; Fuchs et al. 2016; Govoni et al. 2017), neighboring networks of broadband stations available through EIDA (Clinton et al. 2014; Strollo et al. 2021), and the AlpArray Complementary Experiment Swath-D (Heit et al. 2017) (cf. Fig. 1). Similar visualization efforts have been conducted by IRIS as part of the Ground Motion Visualization (GMV: http://ds.iris.edu/ds/products/ gmv/) (IRIS DMC 2010) project, though not with the kind of station density as is available in the Alps today.

We discuss time slices of the wave-fields taken from the animations for specific phase arrivals, to indicate the possibilities opened up by dense regional and local broadband arrays regarding the study of spatial propagation of seismic wavefronts and their usefulness for identifying potential instrumentation problems such as timing errors, and polarity switches. Additional seismogram sections as well as highand low-resolution versions of the animations are provided in the supplementary materials.

\section{Events and data}

Following detailed screening, six representative events have been selected for visualization of seismic wavefields in the AlpArray region (cf. Table 1). The chosen events cover a range of azimuths and distances at similar magnitudes so that their respective features can be reasonably compared. For all events, animations are provided in the supplementary materials. Events are referred to by their number as defined in Table 1 or by their corresponding CMT catalog IDs (Ekström et al. 2012). They include both local and teleseismic examples to illustrate 
Fig. 1 All avail-

able European broadband stations for event No. 1, Taiwan (C201802061550A). See Table 1 for additional information. Triangles mark individual stations, reference stations for Fig. 2 are prominently marked and labeled. Temporary AlpArray component (Z3) in blue, Swath-D (ZS) in red, LOBSTER as white circles, all other networks in gray

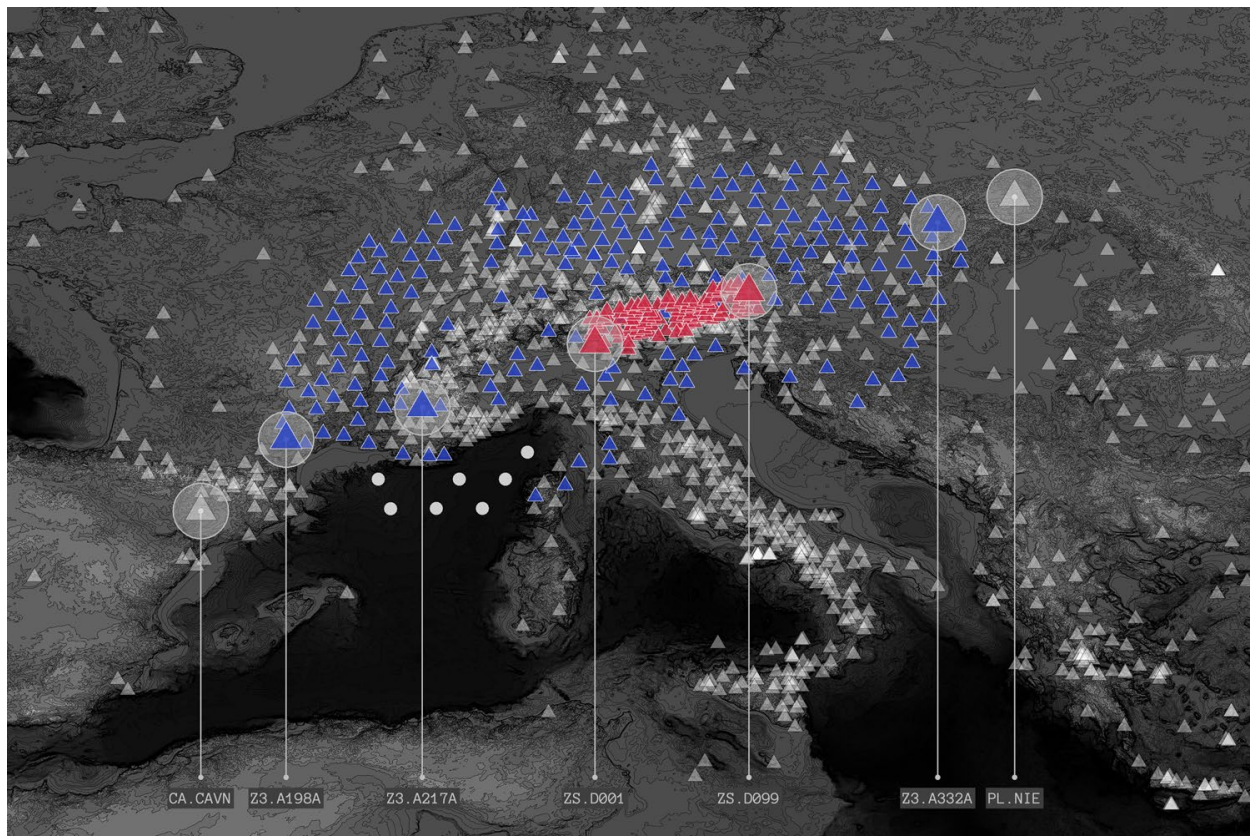

the time-dependent evolution of the seismic wave-fields as well as the spatial resolution capabilities of AlpArray and neighboring European broadband seismic networks for the laterally varying properties of the wave-field.

All available stations within a $20^{\circ}$ radius centered around $45^{\circ} \mathrm{N} 10^{\circ} \mathrm{E}$ are considered. This mid-point is located within the central Po Basin southeast of Milan, Italy, marking the "center" of the greater Alpine region for the purpose of this study. It ranges east-to-west from the Black Sea to the northeast Atlantic and north-to-south from central Norway to northern Africa, though the bulk of the station coverage lies in the Alps. All relative measures such as event distances and azimuths are given in relation to this point. Data are obtained on a per-event basis for as many stations as possible within the considered region.

All available non-restricted European stations with any of LHZ, BHZ, or HHZ channels as well as AlpArray and Swath-D data are downloaded for the selection of events. The download is facilitated by means of the International Federation of Digital Seismograph Networks (FDSN: http://fdsn.org/about/), yielding approximately between 1300 and 1600 stations from over 60 networks per event. The varying data availability reflects the different operational periods of the temporary components. (See list of networks in References.)

All traces are detrended, instrument response-corrected, band-pass filtered between 100 and $500 \mathrm{~s}$, resampled to $1 \mathrm{~Hz}$, and aligned such that they are all sampled in relation to the same time vector.

\section{Methods}

\section{Seismogram sections}

Figure 2 shows an overview of the vertical component dataset for event No. 1 in Taiwan. To emphasize weaker phases, the traces are individually normalized via division by their respective low-pass filtered envelopes (corner frequency of $5 \mathrm{mHz}$ ) and subsequently scaled by a factor of 0.8 . This largely confines the data to the target interval of $[-1,1]$, after which it is clipped in the figures.

Samples of all available traces are averaged into small rectangular bins, $0.02^{\circ}$ by $1 \mathrm{~s}$ in size. The resulting image is shown in black and white in the background of Fig. 2 . Each bin is usually only comprised of the data from a handful of stations. Epicentral distances between ca. $80^{\circ}$ $-92^{\circ}$ provide the greatest resolution, thanks to coverage of AlpArray and Swath-D. At distances of $<78^{\circ}$ and $>92^{\circ}$, some averages may be determined by erroneous data due to lower spatial resolution, therefore, fewer clear arrivals are visible. E.g., at around $92^{\circ}$, two traces featuring spurious long-period anomalies across the entire time window are apparent.

Several reference traces from stations in the AlpArray, Swath-D, as well as the Spanish and Polish networks are superimposed onto the section for comparison. They are shaded with their respective weighting envelopes in red and blue. The station locations and the extent of the AlpArray and Swath-D temporary networks are shown in Fig. 1. 
Fig. 2 Seismogram section for event No. 1, Taiwan (C201802061550A). Seismograms for reference stations shown in Fig. 1 are plotted on top for comparison (in conjunction with their weighting envelopes in red/blue) at their respective epicentral distances, as labeled on the left. See text for further explanations. Time axis is given in minutes after source time. Selected arrivals are labeled according to their corresponding theoretical travel times computed via TauP (Crotwell et al. 1999), i.e., 4S = SSSS, etc.

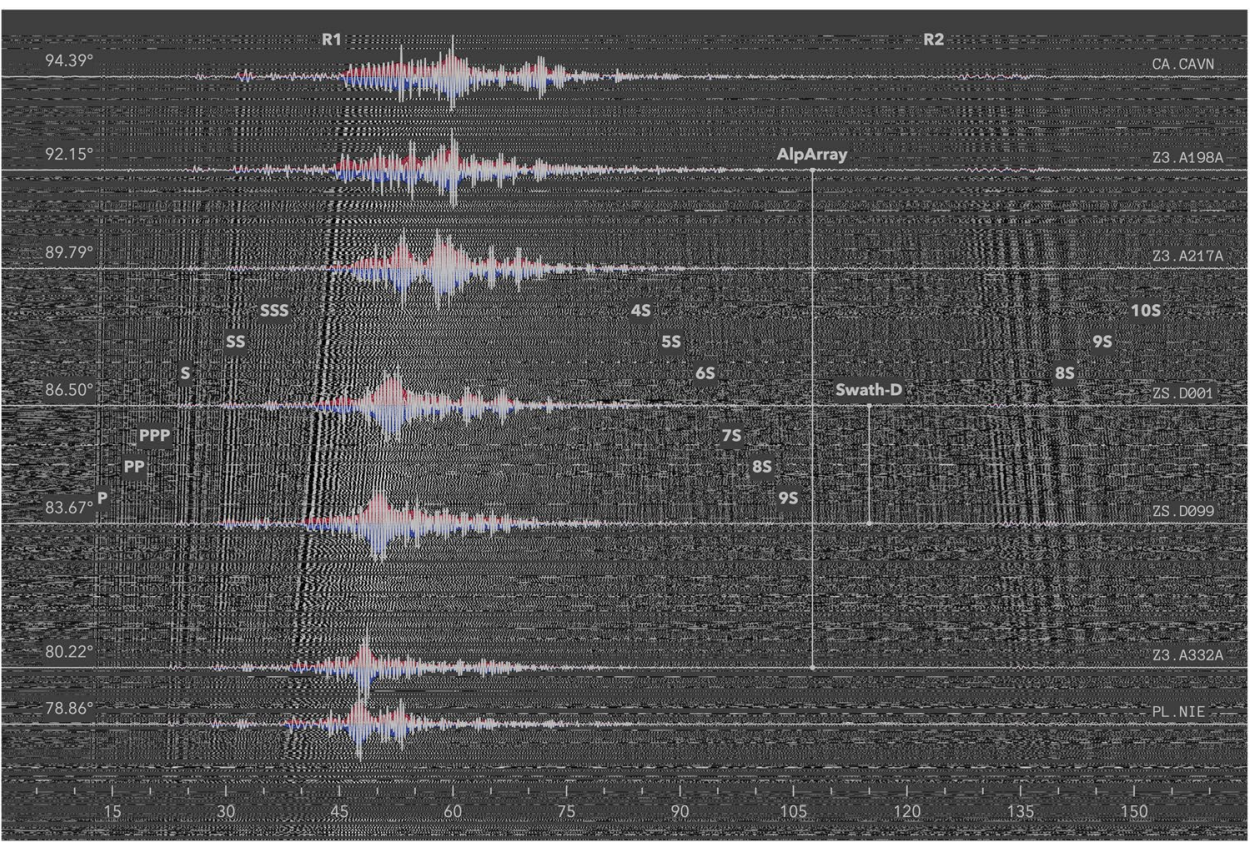

Table 1 The six selected events

\begin{tabular}{lllllll}
\hline & No. 1 & No. 2 & No. 3 & No. 4 & No. 5 & No. 6 \\
\hline CMT ID & C201802061550A & C201801281603A & C201610300640A & C201612251422A & C201801250210A & C201608240136A \\
Location & Taiwan & Southwest of Africa & Central Italy & Southern Chile & Eastern Russia & Central Italy \\
Lat., Lon. & $24.0^{\circ} \mathrm{N}, 121.54^{\circ} \mathrm{E}$ & $53.06^{\circ} \mathrm{S}, 9.95^{\circ} \mathrm{E}$ & $42.75^{\circ} \mathrm{N}, 13.16^{\circ} \mathrm{E}$ & $43.41^{\circ} \mathrm{S}, 74.43^{\circ} \mathrm{W}$ & $55.54^{\circ} \mathrm{N}, 166.5^{\circ} \mathrm{E}$ & $42.64^{\circ} \mathrm{N}, 13.22^{\circ} \mathrm{E}$ \\
Distance & $87.11^{\circ}$ & $98.06^{\circ}$ & $3.2^{\circ}$ & $115.85^{\circ}$ & $77.52^{\circ}$ & $3.31^{\circ}$ \\
Azimuth & $318.8^{\circ}$ & $0.04^{\circ}$ & $315.63^{\circ}$ & $51.6^{\circ}$ & $343.23^{\circ}$ & $316.45^{\circ}$ \\
Back Azimuth & $58.2^{\circ}$ & $180.03^{\circ}$ & $133.44^{\circ}$ & $233.62^{\circ}$ & $13.36^{\circ}$ & $134.22^{\circ}$ \\
Depth & $13.9 \mathrm{~km}$ & $12 \mathrm{~km}$ & $12 \mathrm{~km}$ & $32.8 \mathrm{~km}$ & $12 \mathrm{~km}$ & $12 \mathrm{~km}$ \\
Magnitude & $6.37 M_{W}$ & $6.51 M_{W}$ & $6.59 M_{W}$ & $7.57 M_{W}$ & $6.22 M_{W}$ & $6.2 M_{W}$ \\
Date & $2018-02-06$ & $2018-01-28$ & $2016-10-30$ & $2016-12-25$ & $2018-01-25$ & $2016-08-24$ \\
Time & $15: 50: 48$ & $16: 03: 10$ & $06: 40: 24$ & $14: 22: 38$ & $02: 10: 38$ & 1616 \\
Stations & 1598 & 1609 & 1319 & 1409 & 1616 & 1428 \\
\hline
\end{tabular}

Distances and azimuths relative to $45^{\circ} \mathrm{N}, 10^{\circ} \mathrm{E}$

\section{Animations}

The full spatial complexity of the wave-fields cannot be adequately represented via a seismogram section alone, hence a spatial representation of the data is needed. Such a representation is provided by time slices of the wavefronts in Figs. 3, 4, 5, 6 and 7, as well as by animations of the entire wave-fields (cf. supplementary materials).

To make use of the full dynamic range of the color scale at any time, we apply the same time-dependent normalization of the seismograms at each station as was used for the section (Fig. 2). In addition to the aforementioned processing steps, the traces are band-pass filtered down to a minimum period of $20 \mathrm{~s}$ to ensure a good signal-to-noise ratio and coherent phase arrivals given the available station density. The traces are cut to a length of 220 min starting
10 min before source time for local events (i.e., events No. 3 and 6) and to a length of $165 \mathrm{~min}$ starting at source time for teleseismic events.

Note that the only quality control metric that was used is a basic percentage threshold regarding the number of samples that must be present in an individual trace for it to be used. Data from stations missing more than $10 \%$ of their samples during these time periods are discarded.

The animations are rendered within a rectangular region from $54^{\circ} \mathrm{N} 4^{\circ} \mathrm{W}$ (Great Britain) in the top left to $34^{\circ} \mathrm{N} 26^{\circ} \mathrm{E}$ (Greece) in the bottom right. The playback speed is 30 times faster than real time.

A vertical cursor above the unweighted reference trace at the bottom of the animations indicates the current point in time. The station from which the reference trace was taken is indicated by a triangular marker. The reference trace is 
Fig. $3 \mathrm{P}$ arrivals at $00: 14: 00$ after source time. Location of reference trace at ZS. D0 01 marked with a white triangle. A vertical bar indicates the current point in time in relation to the reference trace (cf. Figs. 4, 5, 6 and 7). Event No. 2, Southwest of Africa (C201801281603A)

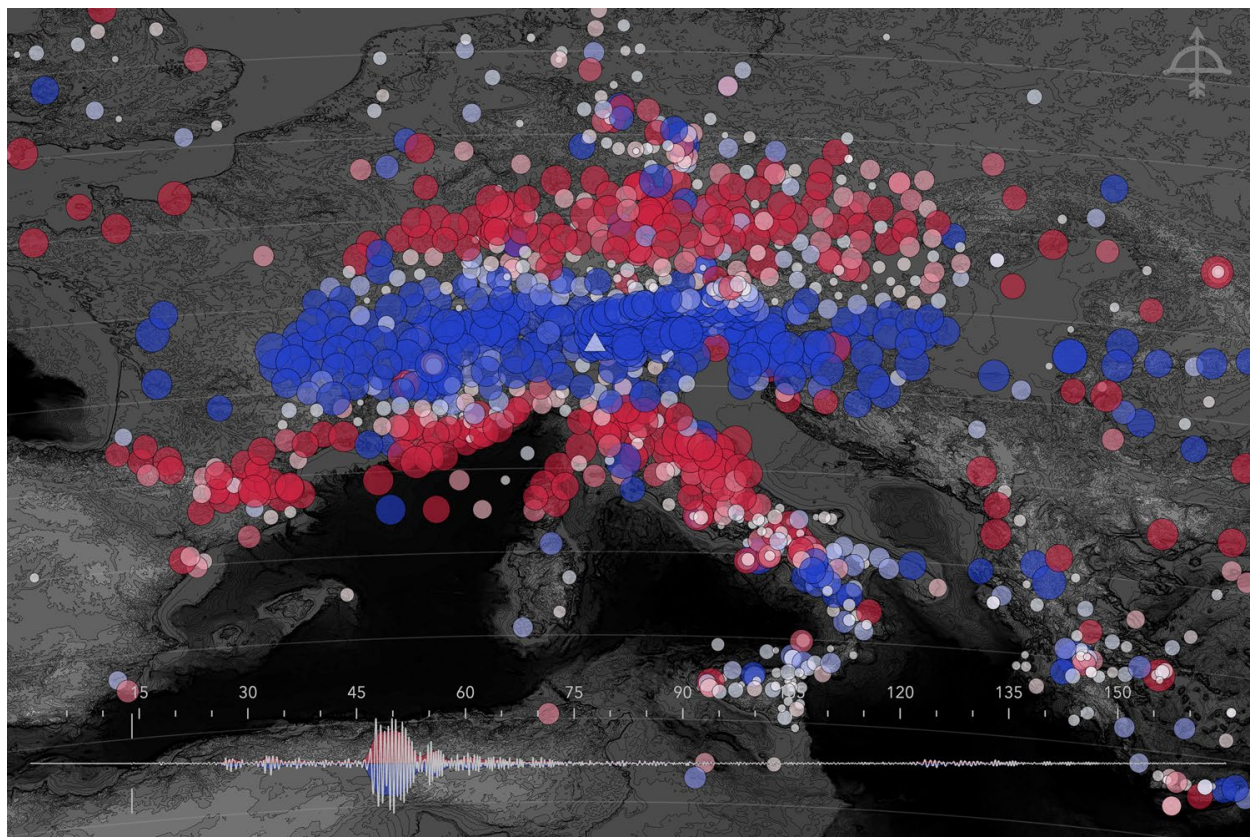

Fig. $4 \mathrm{~S}$ arrivals at $00: 27: 30$ after source time. Location of reference trace at ZS. D0 01 marked with a white triangle. Event No. 2, Southwest of Africa (C201801281603A)

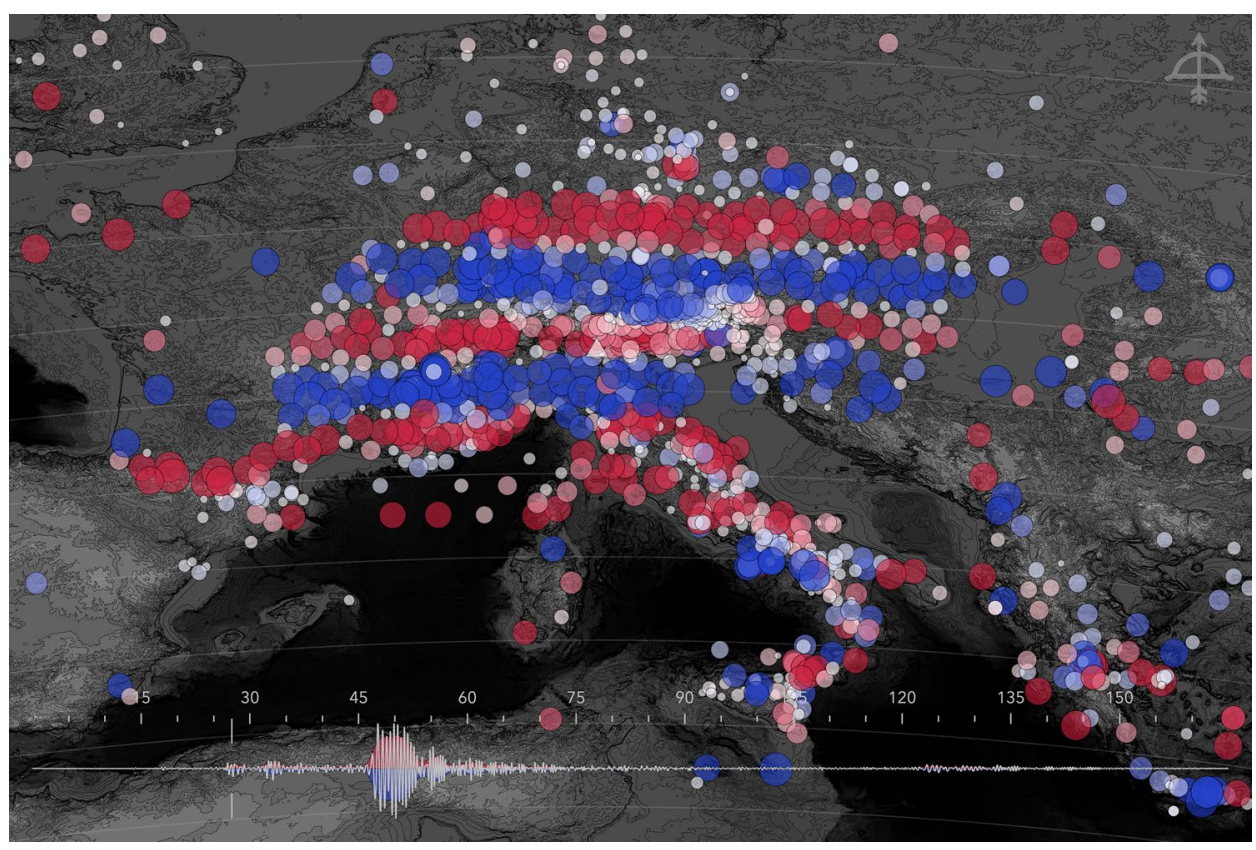

displayed on top of its weighting envelope, like in the seismogram section. The size of the circular station markers are proportional to their current absolute value of the envelope weighted vertical ground velocity and the color encodes the direction of displacement, positive as red and negative as blue. The top-right corner features an arrow indicating the azimuth of the minor arc arrivals. Small circles around the epicenter are included as faint lines at $2^{\circ}$ increments to indicate the approximate shape of the expected wavefronts for the case of a spherically symmetric earth. Deviations of the observed wave-field from these theoretical wavefronts are an indicator of the distortions a phase has experienced due to lateral inhomogeneities along its paths.

\section{Discussion}

\section{Teleseismic events}

The single-event seismogram section of event No. 1 shown in Fig. 2 exhibits a multitude of features associated with the arrival of seismic phases, likely including distinct late 
Fig. $5 \mathrm{R} 1$ arrivals at $00: 42: 50$ after source time. Location of reference trace at $\mathrm{ZS}$. D0 01 marked with a white triangle. Event No. 1, Taiwan (C201802061550A)

Fig. 6 6S, P6S, and related arrivals at $01: 27: 30$ after source time. Location of reference trace at ZS. D0 01 marked with a white triangle. Event No. 2, Southwest of Africa (C201801281603A)
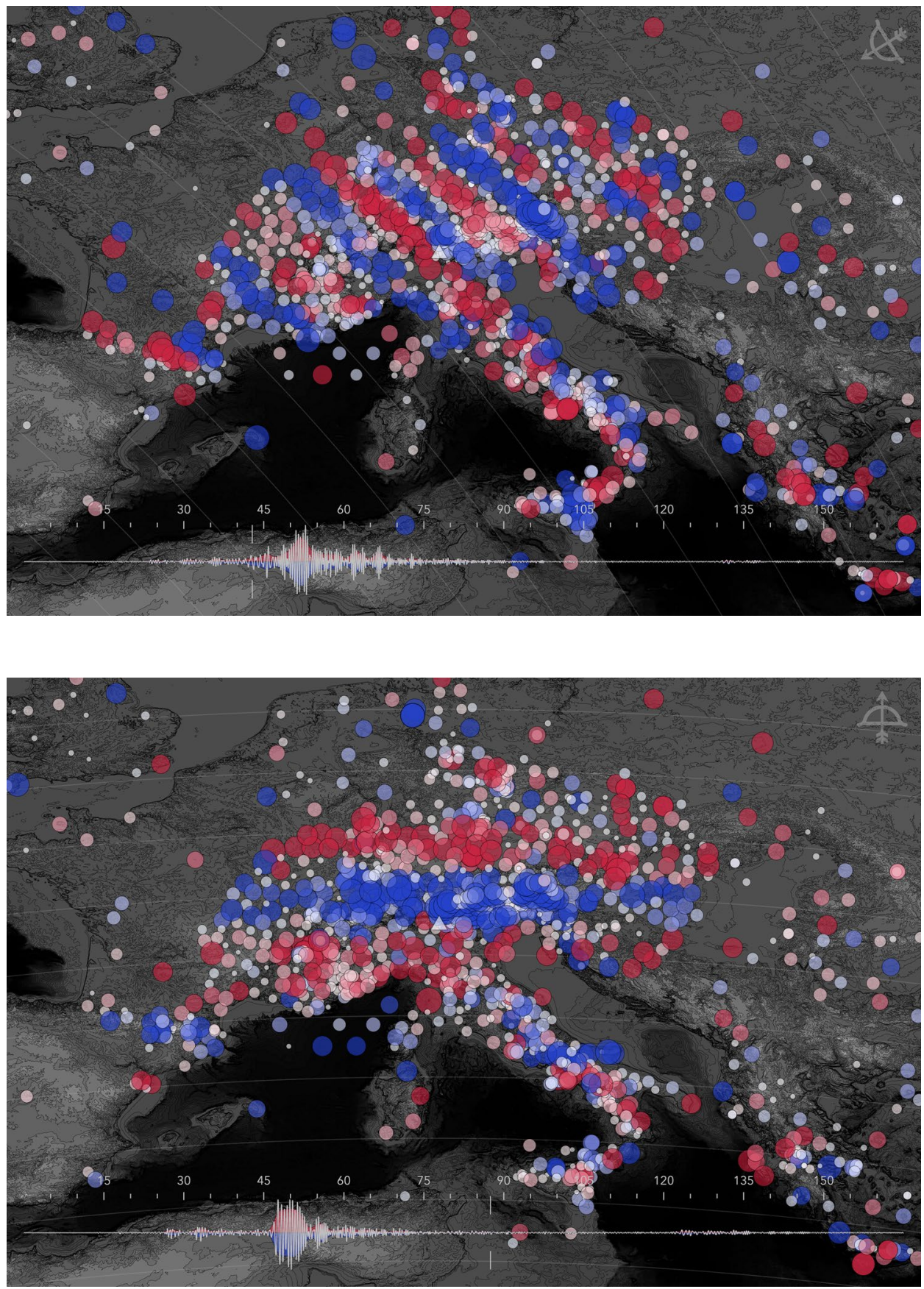

arrivals, a selection of which is labeled according to their respective theoretical travel times. Sections for the other teleseismic events (i.e., No. 2, 4 and 5) can be found in the supplementary materials.

As expected, P, S (cf. Supp. Figs. 1 and 2 for more detail), and SS arrivals are distinctly discernable. In addition, $\mathrm{PP}, \mathrm{PPP}$, and SSS are observed within the distance range of the AlpArray. A number of other early arrivals are visible between PPP and S, as well as between SSS and $\mathrm{R} 1$, though their identification is not immediately obvious, as there exists a set of higher order $\mathrm{P}$ and $\mathrm{S}$ reflections or S-to-P conversions at 410 and $660 \mathrm{~km}$ with similar arrival times which would be expected to superimpose in this range.

The R1 arrival itself is very strong, starting at around $40 \mathrm{~min}$. Once the surface wave coda diminishes after ca. $70 \mathrm{~min}$, several discernable discrete phases are entering the array from the long arc direction, as indicated by their arrival times decreasing with distance. They are only imaged clearly in the distance range of AlpArray, outside of which they become faint and difficult to identify. These phases include 4 S (i.e., SSSS), 5S, and up to $9 \mathrm{~S}$ as well 
Fig. 7 R2 arrivals at $02: 16: 50$ after source time. Location of reference trace at $\mathrm{ZS}$. D0 01 marked with a white triangle. Event No. 1, Taiwan (C201802061550A)

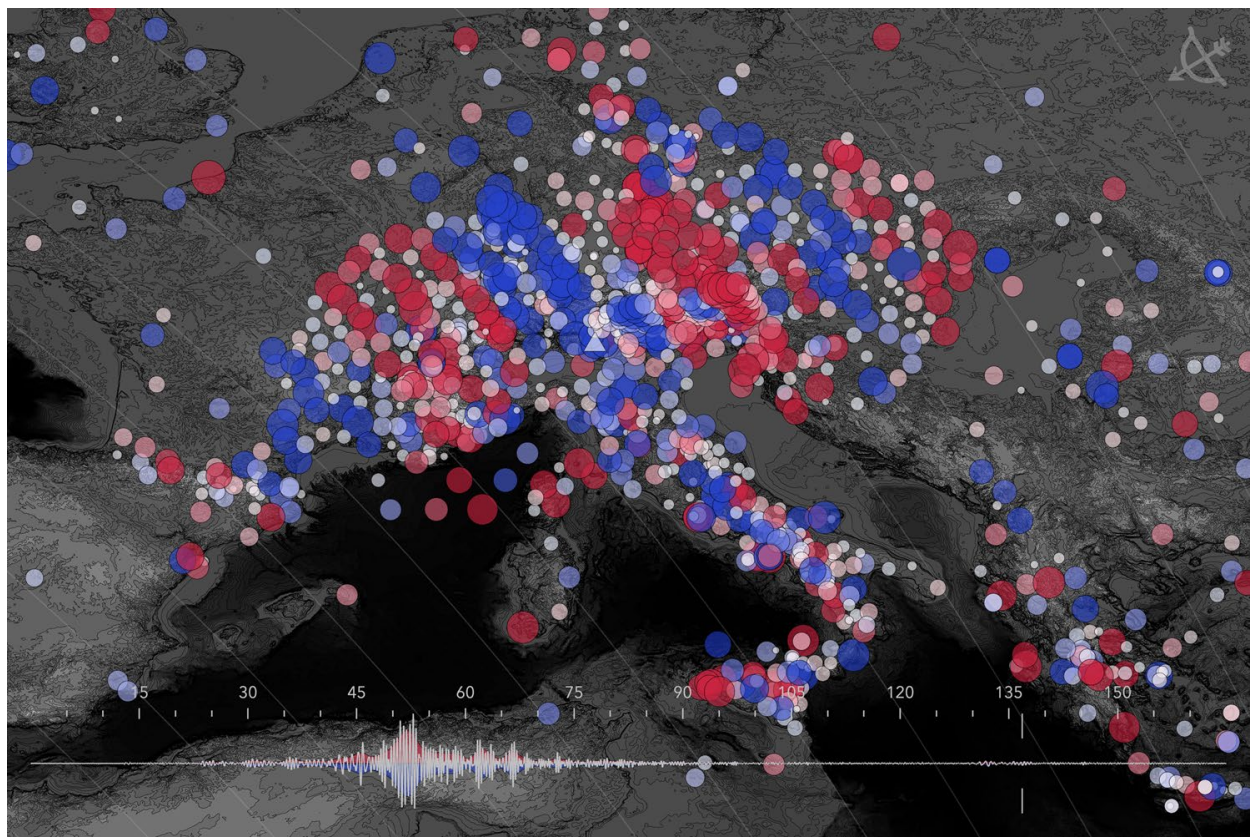

as their related higher order $\mathrm{P}$ reflections, as was confirmed by comparison with theoretical travel times.

At about $130 \mathrm{~min}, \mathrm{R} 2$ enters from the southwest, having taken the opposite path around the globe than all visible arrivals until now. Higher frequencies are significantly reduced due to the longer travel path compared to the minor arc direction of $\mathrm{R} 1$, resulting in a coherent longperiod waveform band stretching out over almost $15 \mathrm{~min}$.

Interestingly, high-order reflected phases even enter the array from the short arc direction shortly after R2, having completed more than one full orbit. They are visible in the time range between ca. 145 and $160 \mathrm{~min}$. Comparison with theoretical travel-time curves shows that these include $8 \mathrm{~S}$, then $9 \mathrm{~S}$, followed by even higher order $\mathrm{S}$ reflections and their respective closely related $P$ phases (i.e., P $8 S$ and PP 8s). To the best of our knowledge, these are the first direct observations of such highly reflected phases in single-event datasets. Previously, it would have been necessary to rely on wave-forms from several events recorded with global station distributions to produce stacked sections that would show body wave phases at this level of complexity (Astiz et al. 1996).

The animations (cf. supplementary materials) depict a broad range of different arrivals, the most prominent of which are discussed here. Some exemplary time slices for body wave arrivals of $P, S$, and $6 S$ for event No. 2 are shown in Figs. 3, 4, and 6 . Figures 5 and 7 show examples of the surface wave arrivals R1 and R2 for event No. 1 . Both events have a moment magnitude of about $M_{w} 6.5$, having taken place at ca. $87^{\circ}$ and $98^{\circ}$ distance away from the center of the Alps, respectively.
Note that the theoretical wavefronts indicated by gray lines in Figs. 5 and 7 (representing small circles around the source) seem to suggest the event is located southwest of the observed region due to their curvature. This is not the case though, as it is merely the result of the equirectangular projection used here, which makes them appear to curve away from the source at greater distances. The source itself is located to the east at a latitude slightly lower than the bottom edge of the figures.

For teleseismic events, the animations start at the event's source time, showing some random but partly coherent wavelets of unrelated phases propagating in arbitrary directions throughout the Alps. The minor arc $\mathrm{P}$ phase arrives after about 14 min (cf. Fig. 3) for event No. 2, coming in from the south. It exhibits the longest horizontal wavelength with about $6^{\circ}-7^{\circ}$. Interestingly, the expected transition from $P$ to $P_{\text {diff }}$ occurs at about the distance of the reference station at the center of the displayed region, though this is not discernable in the animation. The wavefront seems largely aligned with the theoretical wavefront (cf. thin gray lines in Fig. 3). It is closely followed by P P and P P P at ca. 18 and 20 min, respectively, which already show a significantly reduced horizontal wavelength of about $4^{\circ}$, due to the shallower angle formed between their travel paths and the surface. They are also largely unaffected by distortions and appear laterally coherent.

The horizontal wavelength of $\mathrm{P}$ may vary considerably throughout its arrival for some events. Event No. 1 initially shows negative amplitudes over a horizontal width of about $4^{\circ}$ for instance, followed by positive amplitudes over a width of almost $8^{\circ}$. This can be in part a result of source effects 
overprinting the propagation effects, particularly as the event has a relatively long half-duration of $3.7 \mathrm{~s}$, but given the dominant period of $>20 \mathrm{~s}$, it may also be indicative of the weak, but nonetheless present dispersion in body waves (e.g. Futtermann 1962; Wuenschel 1965), though further analysis would be needed to confirm this. Event No. 2 does not exhibit any such variation in wavelength throughout its $P$ phase, for example.

Figure 3 particularly highlights the capability of AlpArray and Swath-D to spatially reconstruct the wave-field within the Alps, as compared to the surrounding regions. The difference between the clear arrival imaged in the eastern Alps and Italy vs. its continuation to the east across the Adriatic and into Eastern Europe is quite striking, as far as freely available data is concerned.

Several higher order $\mathrm{P}$ reflections arrive from about 20 min until the arrival of the $\mathrm{S}$ wave at ca. 27 min (cf. Fig. 4). They appear highly influenced by lateral inhomogenous structure along their paths, being not as clear as the lower order multiples, not always being visible across the full width of the array, and sometimes strongly deviating from the theoretical spherical wavefronts. The $S$ arrival (Fig. 4) shows some small distortion in the form of a slight delay in the Central Alps, as well as shorter horizontal wavelength compared to the previous phases of just about $3^{\circ}$. It is directly followed by a number of converted phases (PS, PPS, etc.) which are again only well resolved in parts of the array. The S S phase is clearly visible as well with similar wavelength and velocity as $\mathrm{S}$ at ca. $33 \mathrm{~min}$. It is immediately followed by PSS at about $34 \mathrm{~min}$. SSS and other higher order body wave phases follow, though they are heavily interfering with one another and cannot be uniquely separated. Nonetheless their superposition can still be observed as a strongly distorted and fragmented wave-field leading up to $\mathrm{R} 1$. These phases are notably more sensitive to $3 \mathrm{D}$ structure, sometimes reaching the array at an oblique angle compared to the theoretical great circle path, which is particularly obvious within the Swath-D network.

For event No. 1 the surface wave R1 reaches the array at ca. $43 \mathrm{~min}$ (cf. Fig. 5), but there is not a clear distinction to the multitude of preceding phases, as the surface wave arrival has a rather emergent characteristic. Its horizontal wavelength is small at less than $2^{\circ}$ and its horizontal velocity is the lowest of all arrivals. Its coda dominates the signal for about $30 \mathrm{~min}$, developing into an incoherent high frequency signal after ca. 52 min when periods shorter than about $20 \mathrm{~s}$ start to become prevalent. Wave-fields of these periods cannot be properly imaged by the available station density, hence they were suppressed during processing via the described filtering. Only few deformed but coherent wavelets are visible within the denser Swath-D in this range in time.

It is worth noting, that because of the normalization procedure used to make the body wave arrivals more visible, surface wave arrivals appear somewhat less prominent than they are in actuality. Despite not appearing as bold as some of the arrivals with longer horizontal wavelengths in these figures, they do of course carry the vast majority of physical energy of the seismic wave-fields.

Only after the coda has sufficiently diminished in amplitude, higher order body wave phases can again be discerned. The visibility of such phases varies from event to event, but there generally is a significant amount of structure of the wave-field still able to be resolved between the two surface wave arrivals. Figure 6 shows one such example of $6 \mathrm{~S}$ entering from the north for event No. 2. These phases have taken the opposite path around the earth, as indicated by the slope of their travel-time curves (cf. Fig. 2 and Supp. Figs. 3-5). They are usually comprised of a bundle of similar phases arriving in close succession, having a fixed number of $S$ reflections and a varying number of $\mathrm{P}$ reflections. For that reason they can sometimes appear quite drawn out and scattered in the animations, as up to a dozen overlapping additional $P$ reflections follow within a few minutes. The identification of these phases was again confirmed using theoretical travel times. Though largely incoherent, the overall structure of the wave-field is still perceptibly different compared to just random noise, such as at the beginning of the animations.

At about 130 min, the major arc surface wave R2 of event No. 1 emerges over the array from the southwest, lasting until ca. $145 \mathrm{~min}$. As a result of its longer orbit it lacks in high frequencies compared to $\mathrm{R} 1$ due to anelastic damping and exhibits strong dispersion as shown by the dramatic increase in wavelength over the course of its arrival due to the increased separation of frequencies at such distances.

Following R2, a number of multi-orbit body wave phases enter the array from the direction of the source. They are extremely spatially distorted and cannot be individually discerned. Nonetheless they create a wave-field that is still distinctly different from random noise, particularly within Swath-D.

Note that time slices of this kind can be useful to spot either individual polarity or timing errors by virtue of comparison to nearby stations. Verifying the spatial consistency of data in such a manner can of course only make sense if the station density is sufficient. Both the figures shown here and the animations clearly point out a few out-of-phase traces, particularly during long wavelength arrivals such as P. Figure 3 shows a few cases at the north-eastern end of the Adriatic (red) or east of Corsica (blue), for example.

\section{Local events}

For local events such as No. 3 and 6, the appearance of the wave-field is somewhat different, as the source is contained within the observed region, allowing for direct observation 
of the wave's inception. Due to the close proximity to the source, all arrivals are seen in close succession, quickly propagating out of the array within a few minutes. The dramatically decreased arrival angle of the body wave phases compared to the teleseismic examples also leads to a significantly reduced horizontal wavelength of less than $2^{\circ}$ for $\mathrm{P}$ and a much lower horizontal propagation velocity. At the periods considered, deformations of the wavefront are almost not discernable in the animations for such short ray paths, because accumulated delays or advances induced by crustal structure are yet too weak to be spatially resolved by the available station density.

After R1 exits, the array the animations of the local events quickly return to noise, as there are no phases reaching the array until the arrival of waves that have completed a full orbit. Noise remains prevalent for about $1 \mathrm{~h}$, after which the first returning phases can be seen. They do not appear as distinct wavefronts but rather as highly scattered and deformed wavelets. This is expected as the superposition of arrivals collapsing back into the source from practically every direction after circling the entire earth is bound to be strongly affected by global 3D structure and the earth's ellipticity. This effect would probably be even more pronounced for larger magnitude earthquakes, though none occurred during operation of the AlpArray network. The arrival of returning scattered higher order reflections continues for well over $100 \mathrm{~min}$. At some points in time the wave-field does coalesce into a semi-coherent ring-like wavefront (e.g., at $90 \mathrm{~min}$ for event No. 3, possibly $10 \mathrm{P} 2 \mathrm{~S}$ and higher as per theoretical travel times), but most of the time it is rather fragmented, sometimes even seemingly forming standing waves between simultaneous arrivals from opposite directions.
The returning Rayleigh wave $\mathrm{R} 2$ takes ca. $168 \mathrm{~min}$ to arrive back at the source. It first enters from the north as an almost planar, surprisingly intact wavefront, slowly shifting to a south-easterly direction of propagation over the next few minutes. Shortly after, R2 arrivals from the south and west become apparent as well and the wave-field becomes very complex again. The dispersive Rayleigh wave coda dominates for ca. $20 \mathrm{~min}$.

Besides potential 3D structure and a cumulatively faster propagation velocity along the path over the poles, the delay in R2 arrivals from the east and west is also likely aided by the ellipticity of the earth and the appreciably shorter poleto-pole radius. The east-to-west propagation path is about $70 \mathrm{~km}$ longer, resulting in an expected delay of about $24 \mathrm{~s}$ for periods around $50 \mathrm{~s}$. It can, therefore, not be the sole reason for the observed behavior, particularly as it would not introduce any incoherency into the wave-field by itself.

\section{Standard deviation}

To assess the level of deformation that is present in the considered wave-fields, we compute the standard deviation for each individual station's unnormalized trace over its entire length of $165 \mathrm{~min}$. Though this includes many phases, the result is mainly dominated by the influence of $\mathrm{R} 1$. This provides a straightforward measure as to how much the wavefield's amplitudes vary in different subregions of the array, which may serve to identify areas of convergent or divergent propagation.

Figure 8 gives the standard deviation for event No. 4 . A strong positive anomaly is visible across the Alpine Arc in form of a bold west-to-east stripe, almost parallel to the
Fig. 8 Standard deviation of vertical ground velocity over a $2: 45 h$ period, starting at source time. Like for the time slices, color and size of the markers encode the same information, i.e., big red circles indicating large deviations and vice versa. Event No. 4, Southern Chile (C201612251422A)

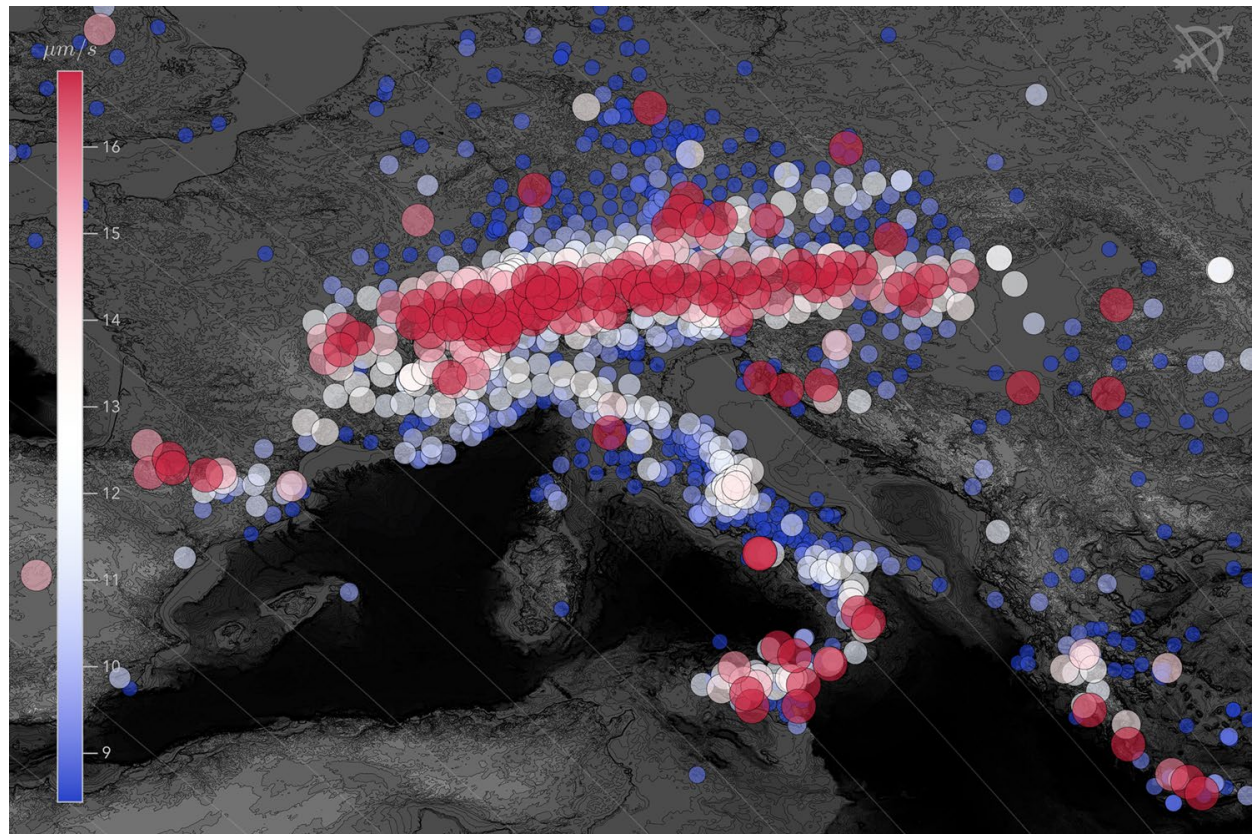


direction of propagation. Such features are not uncommon, with local amplifications being observed for most teleseismic events (cf. Supp. Figs. 6-8). They are likely induced by scattering outside the array (Kolínský and Bokelmann 2019) and highlight the importance of considering and understanding the deformed nature of the wave-fields. Such anomalies cannot be considered indicative of local structure and it is of utmost importance for tomographic techniques operating on data sampled as dense as this to take that into account, e.g., via evaluation of amplitudes in Helmholtz tomography.

Standard deviations may, therefore, serve as a proxy indicator for the deformation of local amplitudes, either due to scattering outside of the array or because of shallow and deep inhomogeneities beneath the array. It has been shown that between 40 and $60 \%$ of amplitude residuals can be explained by surficial sediment layers alone (Weber 1994) but local effects alone can obviously not explain the observed anomalies in this case. To examine these effects in more detail, it might be useful to look at accumulated standard deviations from a broader collection of events in the future, covering the complete azimuth range, to suppress any deformations that occurred outside of the observed region.

\section{Conclusions}

Animations with dynamic gain control showing seismic wave-fields recorded by dense station configurations such as provided by AlpArray, Swath-D, and the European networks within the extended Alpine region, are a useful tool serving educational, quality control, and research purposes. Particularly, their ability to show the full complexity of distorted wavefronts and to image late arriving, multiply reflected, multi-orbit phases based on single event datasets provide a unique opportunity to understand the complex spatio-temporal behavior of seismic waves.

It is apparent that teleseismic wavefronts deviate in part strongly from spherical waves. This holds for $\mathrm{P}$ and $\mathrm{S}$ arrivals and even more so for later phases. One of the most striking observations is the decrease in horizontal wavelength from the earlier body wave to later surface wave arrivals, despite longer periods being of course more prominent in the latter. The short overall horizontal wavelengths of surface waves also highlights the need for dense arrays, as even within AlpArray the spatial resolution is just sufficient to image the main surface wave train without aliasing. The deployment of very dense local arrays like the Swath-D can help to further reduce the shortest resolvable wavelengths, allowing for instance the spatial imaging of surface wave codas, scattered waves, or even ambient noise, at least within smaller subregions.

It remains a challenge to derive information about local structure, because the observed wave-fields are strongly influenced by structure along their paths. This effect manifests itself, e.g., in the observed standard deviation of the seismograms (cf. Fig. 8), which is mainly sensitive to the large amplitudes of the fundamental Rayleigh mode. Strong local amplification by a factor of around two are often observed within the Alpine area, which completely overprint the expected decay of amplitudes with epicentral distance. Such amplifications are often confined to narrow bands oriented almost parallel to the propagation direction (Pollitz 2008; Liang and Langston 2009), pointing to interference of the surface waves with surface waves forward scattered at lateral heterogeneity outside of the array (Kolínský and Bokelmann 2019). Amplitude variations due to inhomogeneities inside the source region can reach a factor of up to 10 over a distance range of $10^{\circ}$ at teleseismic distances (Weber 1990). For 3D modeling including anisotropy and even stronger effects, see Kendall and Thomson (1993).

Thanks to the lateral extent of the regional array, it may also cover the source region for some events, providing the opportunity to directly observe wave propagation over regional distances. It is also worth noting that working with data from dense regional arrays demands an increased focus on quality control and consistency checks, such as correcting wrong timing or faulty station metadata, as the spatial properties of the wave-field are rather susceptible to such errors, particularly in the case of amplitude information. Consulting animations can help to more easily identify these errors.

The data obtained by AlpArray, Swath-D, and the neighboring European networks will be the basis for an improved analysis of seismic wave propagation in a strongly heterogeneous region, enabling new processing methods that take into account the spatial distortions of the wave-fields, leading to a better understanding of the deep structure of the Alpine orogen.

Supplementary Information The online version contains supplementary material available at https://doi.org/10.1007/s00531-021-02116-7.

Acknowledgements We thank the network operators, EIDA, and the members of the AlpArray and Swath-D Working Groups for making this possible. The AlpArray Working Group: György Hetényi, Rafael Abreu, Ivo Allegretti, Maria-Theresia Apoloner, Coralie Aubert, Simon Besançon, Maxime Bès De Berc, Götz Bokelmann, Didier Brunel, Marco Capello, Martina Čarman, Adriano Cavaliere, Jérôme Chèze, Claudio Chiarabba, John Clinton, Glenn Cougoulat, Wayne C. Crawford, Luigia Cristiano, Tibor Czifra, Ezio D’Alema, Stefania Danesi, Romuald Daniel, Anke Dannowski, Iva Dasović, Anne Deschamps, Jean-Xavier Dessa, Cécile Doubre, Sven Egdorf, Ethz-Sed Electronics Lab, Tomislav Fiket, Kasper Fischer, Wolfgang Friederich, Florian Fuchs, Sigward Funke, Domenico Giardini, Aladino Govoni, Zoltán Gráczer, Gidera Gröschl, Stefan Heimers, Ben Heit, Davorka Herak, Marijan Herak, Johann Huber, Dejan Jarić, Petr Jedlička, Yan Jia, Hélène Jund, Edi Kissling, Stefan Klingen, Bernhard Klotz, Petr Kolínský, Heidrun Kopp, Michael Korn, Josef Kotek, Lothar Kühne, Krešo Kuk, Dietrich Lange, Jürgen Loos, Sara Lovati, Deny Malengros, Lucia Margheriti, Christophe Maron, Xavier Martin, Marco Massa, Francesco Mazzarini, Thomas Meier, Laurent Métral, 
Irene Molinari, Milena Moretti, Anna Nardi, Jurij Pahor, Anne Paul, Catherine Péquegnat, Daniel Petersen, Damiano Pesaresi, Davide Piccinini, Claudia Piromallo, Thomas Plenefisch, Jaroslava Plomerová, Silvia Pondrelli, Snježan Prevolnik, Roman Racine, Marc Régnier, Miriam Reiss, Joachim Ritter, Georg Rümpker, Simone Salimbeni, Marco Santulin, Werner Scherer, Sven Schippkus, Detlef SchulteKortnack, Vesna Šipka, Stefano Solarino, Daniele Spallarossa, Kathrin Spieker, Josip Stipčević, Angelo Strollo, Bálint Süle, Gyöngyvér Szanyi, Eszter Szücs, Christine Thomas, Martin Thorwart, Frederik Tilmann, Stefan Ueding, Massimiliano Vallocchia, Luděk Vecsey, René Voigt, Joachim Wassermann, Zoltán Wéber, Christian Weidle, Viktor Wesztergom, Gauthier Weyland, Stefan Wiemer, Felix Wolf, David Wolyniec, Thomas Zieke, Mladen Živčić, Helena Žlebčíková The Swath-D Working Group: Ben Heit, Michael Weber, Christian Haberland, Frederik Tilmann (Helmholtz-Zentrum Potsdam Deutsches GeoForschungsZentrum [GFZ]) and the Swath-D Field Team: Luigia Cristiano, Peter Pilz, Camilla Cattania, Francesco Maccaferri, Angelo Strollo, Susanne Hemmleb, Stefan Mroczek, Thomas Zieke, Günter Asch, Peter Wigger, James Mechie, Karl Otto, Patricia Ritter, Djamil Al-Halbouni, Alexandra Mauerberger, Ariane Siebert, Leonard Grabow, Xiaohui Yuan, ChristophSens-Schonfelder, Jennifer Dreiling, Rob Green, Lorenzo Mantiloni, Jennifer Jenkins, Alexander Jordan, Azam Jozi Najafabadi, Susanne Kallenbach (Helmholtz-Zentrum Potsdam Deutsches GeoForschungsZentrum [GFZ]), Ludwig Kuhn, Florian Dorgerloh, Stefan Mauerberger, Jan Seidemann (Universität Potsdam), Rens Hofman (Freie Universität Berlin), Nikolaus Horn, Stefan Weginger, Anton Vogelmann (Austria: Zentralanstalt für Meteorologie und Geodynamik [ZAMG]), Simone Kasemann (Universität Bremen), Claudio Carraro, Corrado Morelli (Südtirol/Bozen: Amt für Geologie und Baustoffprüfung), Günther Walcher, Martin Pernter, Markus Rauch (Civil Protection Bozen), Giorgio Duri, Michele Bertoni, Paolo Fabris (Istituto Nazionale di Oceanografia e di Geofisica Sperimentale [OGS] [CRS Udine]), Andrea Franceschini, Mauro Zambotto, Luca Froner, Marco Garbin (also OGS) (Ufficio Studi Sismici e GeotecniciTrento) Special thanks also to Lars Ottemöller, Petr Kolínský, and the anonymous reviewers who provided thoughtful feedback that helped to improve the manuscript.

Funding Open Access funding enabled and organized by Projekt DEAL. This work was funded by the DFG within the $4 \mathrm{D}-\mathrm{MB}$ project.

Data availability AlpArray and Swath-D data are currently restricted. They will be openly available on 1st of April 2022.

Code availability The code used to create the contents of this work is not currently publicly available.

\section{Declarations}

Conflict of interest The authors do not have any conflicts of interest regarding the work.

Open Access This article is licensed under a Creative Commons Attribution 4.0 International License, which permits use, sharing, adaptation, distribution and reproduction in any medium or format, as long as you give appropriate credit to the original author(s) and the source, provide a link to the Creative Commons licence, and indicate if changes were made. The images or other third party material in this article are included in the article's Creative Commons licence, unless indicated otherwise in a credit line to the material. If material is not included in the article's Creative Commons licence and your intended use is not permitted by statutory regulation or exceeds the permitted use, you will need to obtain permission directly from the copyright holder. To view a copy of this licence, visit http://creativecommons.org/licenses/by/4.0/.

\section{References}

AlpArray Science Plan (2013). http://www.alparray.ethz.ch/export/ sites/alparray/.galleries/dwn-experiments/AlpArray-Dokus.pdf. Accessed 23 Nov 2021

Argand E (1916) Sur l'arc des Alpes Occidentales

Astiz L, Earle P, Shearer P (1996) Global stacking of broadband seismograms. Seismol Res Lett 67(4):8-18

Buttkus et al (1986) Ten years of the Gräfenberg array, defining the frontiers of broadband seismology. Geologisches Jahrbuch, Band E 35. ISBN:978-3-510-96051-4

Clinton J, Hanka W, Mazza S, Pederson H, Sleeman R, Stammler K, Stroll, A, van Eck T (2014) EIDA: the European distributed data archive for seismology. In: Conference on earthquake engineering and seismology

Crotwell HP, Owens TJ, Ritsema J (1999) The TauP toolkit-flexible seismic travel-time and ray-path utilities. Geophys J Int 110(3):501-517. https://doi.org/10.1785/gssrl.70.2.154

Díaz J et al (2007) The IBERARRAY broadband seismic network: a new tool to investigate the deep structure beneath Iberia. ORFEUS Newsletter vol 8

Ekström G, Nettles M, Dziewonski AM (2012) The global CMT project 2004-2010: centroid-moment tensors for 13,017 earthquakes. Phys Earth Planet Inter 200-201:1-9. https://doi.org/10.1016/j. pepi.2012.04.002

Faccenna C, Becker TW, Lucente FP, Jolivet L, Rossetti F (2001) History of subduction and back arc extension in the Central Mediterranean. Geophys J Int 145:809-820. https://doi.org/10.1046/j. 0956-540x.2001.01435.x

Faccenna C, Piromallo C, Crespo-Blanc A, Jolivet L, Rossetti F (2004) Lateral slab deformation and the origin of the western Mediterranean arcs. Tectonics. https://doi.org/10.1029/2002TC001488

Friederich W, Meier T (2011) Temporary seismic broadband network acquired data on Hellenic subduction zone. Eos Sci News 89(40):378. https://doi.org/10.1029/2008EO400002

Fuchs F, Kolínský P, Gröschl G, Bokelmann G, Govoni A (2016) AlpArray in Austria and Slovakia: technical realization, site description and noise characterization. Adv Geosci 43:1-13

Futtermann WI (1962) Dispersive body waves. J Geophys Res 67(13):5279-5291. https://doi.org/10.1029/JZ067i013p05279

Govoni A et al (2017) AlpArray-Italy: site description and noise characterization, vol 43. Copernicus Publications, Göttingen. https:// doi.org/10.5194/adgeo-43-39-2017

Handy MR, Schmid SM, Bousquet R, Kissling E, Bernoulli D (2010) Reconciling plate-tectonic reconstructions of Alpine Tethys with the geological-geophysical record of spreading and subduction in the Alps. Earth Sci Rev 102:121-158. https://doi.org/10.1016/j. earscirev.2010.06.002

Heit B, Weber M, Tilmann F, Haberland C, Jia Y, Pesaresi D (2017) The Swath-D seismic network in Italy and Austria. https://doi.org/ 10.14470/MF7562601148

Hetényi G et al (2018) The AlpArray seismic network: a large-scale European experiment to image the Alpine orogen. Surv Geophys 39:1009-1033. https://doi.org/10.1007/s10712-018-9472-4

Igel H, Weber M (1996) P-SV wave propagation in the Earth's mantle using finite differences: application to heterogeneous lowermost mantle structure. Geophys Res Lett 23:415-418

Igel H, Weber M (1995) SH-wave propagation in the whole mantle using high-order finite differences. Geophys Res Lett 22(6):731-734

IRIS DMC (2010) Data services products: GMV, the ground motion visualization. https://doi.org/10.17611/ds/gmv.1

IRIS Transportable Array (2003) USArray transportable array, international federation of digital seismograph networks. Dataset/seismic network. https://doi.org/10.7914/SN/TA 
Kendall J-M, Thomson CJ (1993) Seismic modelling of subduction zones with inhomogeneity and anisotropy: teleseismic P-wavefront tracking. Geophys J Int 112:39-66. https://doi.org/10.1111/j. 1365-246X.1993.tb01435.x

Kolínský P, Bokelmann G (2019) AlpArray Working Group, arrival angles of teleseismic fundamental mode Rayleigh waves across the AlpArray. Geophys J Int 218(1):115-144. https://doi.org/ $10.1093 / \mathrm{gji} / \mathrm{ggz} 081$

Liang C, Langston CA (2009) Wave gradiometry for USArray: Rayleigh waves. J Geophys Res. https://doi.org/10.1029/2008J B005918

Lugeon M (1902) Les Grandes Nappes de Recouvrement des Alpes du Chablais et de la Suisse. Bulletin de la Société Géologique de France 4:723

Meltzer A, Rudnick R, Zeitler P, Levander A, Humphreys G, Karlstrom K, Ekström G, Carlson R, Dixon T, Gurnis M, Shearer P, van der Hilst R (1999) USArray initiative, GSA Today, pp 8-10

Molinari I, Clinton J, Kissling E, Hetényi G, Giardini D, Stipčević J, Dasović I, Herak M, Šipka V, Wéber Z, Gráczer Z, Solarino $S$ (2016) The Swiss-AlpArray Field Team, and the AlpArray Working Group, Swiss-AlpArray temporary broadband seismic stations deployment and noise characterization. Adv Geosci 43:15-29. https://doi.org/10.5194/adgeo-43-15-2016

Muirhead KJ, Datt R (1976) The N-th root process applied to seismic array data. Geophys J Int 47(1):197-210

Müller G, Kind R (1976) Observed and computed seismogram sections for the whole Earth. Geophys J Int 44(3):699-716

Oliver J, Murphy L (1971) WWNSS: seismology's global network of observing stations. Science 174(4006):254-261. https://doi.org/ 10.1126/science.174.4006.254

Paul A et al (2008) The SIMBAAD experiment in W-Turkey and Greece: a dense seismic network to study the crustal and mantle structures. American Geophysical Union

Pollitz F (2008) Observations and interpretation of fundamental mode Rayleigh wave-fields recorded by the transportable array (USArray). J Geophys Res. https://doi.org/10.1029/2007JB005556

Price NJ, McClay KR (1981) Thrust and nappe tectonics. The Geololgical Society of London, London

Rebeur-Paschwitz E (1889) The earthquake of Tokio 18. April 1889. Nature 40:294-295. https://doi.org/10.1038/040294e0

Strollo A et al (2021) EIDA: the European integrated data archive and service infrastructure within ORFEUS. Seismol Res Lett 92(3):1788-1795. https://doi.org/10.1785/0220200413

Termier P (1906) La Synthèse Géologique des Alpes

Thybo H et al (2021) ScanArray - a broadband seismological experiment in the Baltic shield. Seismol Res Lett 92(5):2811-2823. https://doi.org/10.1785/0220210015

TOR Working Group, Gregersen S, Voss P (2002) Summary of project TOR: delineation of a stepwise, sharp, deep lithosphere transition across Germany-Denmark-Sweden. Tectonophysics 360(1-4):61-73. https://doi.org/10.1016/S0040-1951(02) 00347-5

Vignaroli G, Faccenna C, Jolivet L, Piromallo C, Rossetti F (2008) Subduction polarity reversal at the junction between the western Alps and the northern Apennines, Italy. Tectonophysics 450:34 50. https://doi.org/10.1016/j.tecto.2007.12.012

Vignaroli G, Faccenna C, Rossetti F, Jolivet L (2009) Insights from the Apennines metamorphic complexes and their bearing on the kinematics evolution of the orogen. Geol Soc Lond Spec Publ 311:235-256. https://doi.org/10.1144/SP311.9

Weber M (1990) Subduction zones: their influence on traveltimes and amplitudes of P-waves. Geophys J Int 101:529-544. https://doi. org/10.1111/j.1365-246X.1990.tb05568.x

Weber M (1994) Traveltime and amplitude anomalies at the seismic broad-band array GRF. Geophys J Int 118:57-74. https://doi.org/ 10.1111/j.1365-246X.1994.tb04675.x
Wilde-Piórko M et al (2008) PASSEQ 2006-2008: passive seismic experiment in trans-European suture zone. Studia Geophysica et Geodaetica 52:439-448

Wuenschel PC (1965) Dispersive body waves - an experimental study Geophysics 30(4):493-667. https://doi.org/10.1190/1.1439620

Wysession ME, Shore PJ (1994) Visualization of whole mantle propagation of seismic shear energy using normal mode summation. Pure Appl Geophys 142(2):295-310

\section{Networks}

Albuquerque Seismological Laboratory (ASL)/USGS (1988) Global Seismograph Network (GSN-IRIS/USGS). Dataset/Seismic Network, International Federation of Digital Seismograph Networks. https://doi.org/10.7914/SN/IU

AlpArray Seismic Network (2015) AlpArray Seismic Network (AASN) Temporary Component. AlpArray Working Group. https://doi.org/ 10.12686/ALPARRAY/Z3_2015

Aristotle University of Thessaloniki Seismological Network (1981) Permanent Regional Seismological Network operated by the Aristotle University of Thessaloniki. Dataset/Seismic Network. International Federation of Digital Seismograph Networks. https:// doi.org/10.7914/SN/HT

Bogazici University Kandilli Observatory and Earthquake Research Institute (2001) Bogazici University Kandilli Observatory and Earthquake Research Institute. Dataset/Seismic Network. International Federation of Digital Seismograph Networks. https://doi. org/10.7914/SN/KO

CERN Seismic Network (C4)

Cesca S, López Comino JÁ, Kühn D, Dahm T (2016) Array in Wittewierum, Netherlands. GFZ Data Services. https://doi.org/10. 14470/6P7561560569

Corinth Rift Laboratory Team And RESIF Datacenter (2013) CLCorinth Rift Laboratory Seismological Network (CRLNET). RESIF-Réseau Sismologique et géodésique Français. https://doi. org/10.15778/RESIF.CL

Croatian Seismograph Network (CR). https://doi.org/10.7914/SN/CR

Danish Seismological Network (DK)

Department of Earth and Environmental Sciences, Geophysical Observatory, University of Munchen (2001) BayernNetz. Dataset/Seismic Network. International Federation of Digital Seismograph Networks. https://doi.org/10.7914/SN/BW

Deschamps A, Beucler E (2013) POSA experiment. RESIF-Réseau Sismologique et géodésique Français. https://doi.org/10.15778/ RESIF.ZH2016

Dr. Margarita Segou, Dr. John McCloskey, Dr. Brian Baptie, Dr. David Hawthorn (2016). Armatrice Sequence International. Dataset/ Seismic Network. International Federation of Digital Seismograph Networks. https://doi.org/10.7914/SN/YR_2016

ESI SAS (Earth Science Institute of the Slovak Academy of Sciences) (2004) National Network of Seismic Stations of Slovakia. Deutsches GeoForschungsZentrum GFZ. https://doi.org/10. 14470/FX099882

Estonian Seismic Network (EE)

Federal Institute for Geosciences and Natural Resources (BGR) (1976) German Regional Seismic Network (GRSN). Federal Institute for Geosciences and Natural Resources (BGR). https://doi.org/10. 25928/MBX6-HR74

French Landslide Observatory-Seismological Datacenter/RESIF (2006) Observatoire Multi-disciplinaire des Instabilités de Versants. Centre de données sismologiques/RESIF (Réseau Sismologique et géodésique Français). https://doi.org/10.15778/RESIF.MT

Friedrich Schiller University Jena and Thuringian Institute of Environment and Geology (2009) Thüringer Seismologisches Netz 
(TSN). Dataset/Seismic Network. International Federation of Digital Seismograph Networks. https://doi.org/10.7914/SN/TH

GEOFON Data Centre (1993) GEOFON Seismic Network. Deutsches GeoForschungsZentrum GFZ. https://doi.org/10.14470/TR560 404

Geological and Seismological Institute of Moldova (2007) Moldova Digital Seismic Network. Dataset/Seismic Network. International Federation of Digital Seismograph Networks. https://doi.org/10. 7914/SN/MD

Geological Survey Department Cyprus (2013) Cyprus Broadband Seismological Network. Dataset/Seismic Network. International Federation of Digital Seismograph Networks. https://doi.org/10. 7914/SN/CQ

Geological Survey-Provincia Autonoma di Trento (1981) Trentino Seismic Network. Dataset/Seismic Network. International Federation of Digital Seismograph Networks. https://doi.org/10.7914/ $\mathrm{SN} / \mathrm{ST}$

Great Britain Seismograph Network

Guéguen P, Coutant O, Langlais M (2017) Maurienne Seismic Swarm 2017-2018. RESIF-Réseau Sismologique et géodésique Français. https://doi.org/10.15778/RESIF.YW2017

Heit B, Weber M, Tilmann F, Haberland C, Jia Y, Carraro C, Pesaresi D (2017) The Swath-D Seismic Network in Italy and Austria. GFZ Data Services. https://doi.org/10.14470/MF7562601148

Hessischer Erdbebendienst (HS). https://doi.org/10.7914/SN/HS

INGV Experiments Network (TV)

INGV Seismological Data Centre (2006, January 1). Rete Sismica Nazionale (RSN). Istituto Nazionale di Geofisica e Vulcanologia (INGV), Italy. https://doi.org/10.13127/SD/X0FXNH7QFY

INSN (1993) Irish National Seismic Network, operated by the Dublin Institute for Advanced Studies. Dataset/Seismic Network. International Federation of Digital Seismograph Networks. https://doi. org/10.7914/SN/EI

Institut Cartogràfic i Geològic de Catalunya (1984) Catalan Seismic Network. Dataset/Seismic Network. International Federation of Digital Seismograph Networks. https://doi.org/10.7914/SN/CA

Institut De Physique Du Globe De Paris (IPGP) \& Ecole Et Observatoire Des Sciences De La Terre De Strasbourg (EOST) (1982) GEOSCOPE, French Global Network of broad band seismic stations. Institut de Physique du Globe de Paris (IPGP). https://doi. org/10.18715/GEOSCOPE.G

Institute of Geophysics, Academy of Sciences of the Czech Republic (1973) Czech Regional Seismic Network. Dataset/Seismic Network. International Federation of Digital Seismograph Networks. https://doi.org/10.7914/SN/CZ

Institute of Geosciences, Energy, Water and Environment (2002) Albanian Seismological Network. Dataset/Seismic Network. International Federation of Digital Seismograph Networks. https://doi. org/10.7914/SN/AC

Institute of Seismology, U. O. H. (1980) The Finnish National Seismic Network. GFZ Data Services. https://doi.org/10.14470/UR044600

Instituto Geografico Nacional, Spain (1999) Spanish Digital Seismic Network. Dataset/Seismic Network. International Federation of Digital Seismograph Networks. https://doi.org/10.7914/SN/ES

International Miscellaneous Stations (IM)

ISNet-Irpinia Seismic Network (IX)

Jean-Philippe Malet, Mathilde Radiguet, Clément Hibert (2015) French Landslide Observatory-OMIV (Temporary data). International Federation of Digital Seismograph Networks. Dataset/Seismic Network. https://doi.org/10.15778/RESIF.MT

Kövesligethy Radó Seismological Observatory (Geodetic And Geophysical Institute, Research Centre for Astronomy and Earth Sciences, Hungarian Academy of Sciences (MTA CSFK GGI KRSZO)) (1992) Hungarian National Seismological Network. Deutsches GeoForschungsZentrum GFZ. https://doi.org/10. 14470/UH028726
Laboratorio Subterraneo de Canfranc (2011) LSC (Laboratorio Subterraneo Canfranc). Dataset/Seismic Network. International Federation of Digital Seismograph Networks. https://doi.org/ $10.7914 / \mathrm{SN} / \mathrm{LC}$

Leipzig University (2001) SXNET Saxon Seismic Network. Dataset/ Seismic Network. International Federation of Digital Seismograph Networks. https://doi.org/10.7914/SN/SX

MedNet Project Partner Institutions (1990, January 1) Mediterranean Very Broadband Seismographic Network (MedNet). Istituto Nazionale di Geofisica e Vulcanologia (INGV), Italy. https:// doi.org/10.13127/SD/FBBBTDTD6Q

National Institute for Earth Physics (NIEP Romania) (1994). Romanian Seismic Network. Dataset/Seismic Network. International Federation of Digital Seismograph Networks. https://doi.org/ 10.7914/SN/RO

National Institute of Geophysics, Geodesy and Geography-BAS (1980) National Seismic Network of Bulgaria. Dataset/Seismic Network. International Federation of Digital Seismograph Networks. https://doi.org/10.7914/SN/BS

National Observatory of Athens, Institute of Geodynamics, Athens (1997) National Observatory of Athens Seismic Network. Dataset/Seismic Network. International Federation of Digital Seismograph Networks. https://doi.org/10.7914/SN/HL

Norwegian Seismic Array Network (NO)

OGS (Istituto Nazionale di Oceanografia e di Geofisica Sperimentale) (2016) North-East Italy Seismic Network. Dataset/Seismic Network. International Federation of Digital Seismograph Networks. https://doi.org/10.7914/SN/OX

OGS (Istituto Nazionale di Oceanografia e di Geofisica Sperimentale) and University of Trieste (2002) North-East Italy Broadband Network. Dataset/Seismic Network. International Federation of Digital Seismograph Networks. https://doi.org/10.7914/ $\mathrm{SN} / \mathrm{NI}$

Polish Seismological Network (PL)

Portuguese National Seismic Network (PM). https://doi.org/10.7914/ $\mathrm{SN} / \mathrm{PM}$

Province Südtirol (SI)

RESIF (1995) RESIF-RLBP French broadband network, RESIF-RAP strong motion network and other seismic stations in metropolitan France. RESIF-Réseau Sismologique et géodésique Français. https://doi.org/10.15778/RESIF.FR

RESIF (2018) CEA/DASE broadband permanent network in metropolitan France. RESIF-Réseau Sismologique et géodésique Français. https://doi.org/10.15778/RESIF.RD

Royal Observatory of Belgium (1985) Belgian Seismic Network. Dataset/Seismic Network. International Federation of Digital Seismograph Networks. https://doi.org/10.7914/SN/BE

San Fernando Royal Naval Observatory (ROA), Universidad Complutense De Madrid (UCM), Helmholtz-Zentrum Potsdam Deutsches GeoForschungsZentrum (GFZ), Universidade De Evora (UEVORA, Portugal), Institute Scientifique Of RABAT (ISRABAT, Morocco) (1996) The Western Mediterranean BB seismic Network. Deutsches GeoForschungsZentrum GFZ. https://doi.org/10.14470/JZ581150

Scripps Institution of Oceanography (1986) IRIS/IDA Seismic Network. Dataset/Seismic Network. International Federation of Digital Seismograph Networks. https://doi.org/10.7914/SN/II

Sector for Seismology, Institute of Hydrometeorology and Seismology of Montenegro (1982) Montenegrin Seismic Network. Dataset/Seismic Network. https://doi.org/10.7914/SN/ME

Seismic Network of Tunisia (TT)

Serbian Seismological Network (SJ)

Slovenian Environment Agency (2001) Seismic Network of the Republic of Slovenia. Dataset/Seismic Network. International Federation of Digital Seismograph Networks. https://doi.org/ $10.7914 / \mathrm{SN} / \mathrm{SL}$ 
Swiss Seismological Service (SED) at ETH Zurich (1983) National Seismic Networks of Switzerland. ETH Zürich. https://doi.org/ 10.12686/SED/NETWORKS/CH

Technological Educational Institute of Crete (2006) Seismological Network of Crete. Dataset/Seismic Network. International Federation of Digital Seismograph Networks. https://doi.org/10.7914/SN/HC

UK Schools Seismic Network (UK)

UK-Net, Blacknest Array (BN)

UniBAS (BA)

University of Athens (2008) University of Athens. International Federation of Digital Seismograph Networks. Dataset/Seismic Network, Seismological Laboratory. https://doi.org/10.7914/SN/HA

University of Bari “Aldo Moro" (2013) OTRIONS. International Federation of Digital Seismograph Networks. Dataset/Seismic Network, Seismic networks of Gargano Area (Italy). https://doi.org/ $10.7914 / \mathrm{SN} / \mathrm{OT}$

University of Genova (1967) Regional Seismic Network of North Western Italy. Dataset/Seismic Network. International Federation of Digital Seismograph Networks. https://doi.org/10.7914/SN/GU
University of Lisbon Seismic Network (LX)

University of Patras, Geology Department, Seismological Laboratory (2000) PSLNET, permanent seismic network operated by the University of Patras. International Federation of Digital Seismograph Networks. Dataset/Seismic Network, Greece. https://doi.org/10. 7914/SN/HP

University of Trieste (1993) Friuli Venezia Giulia Accelerometric Network. Dataset/Seismic Network. International Federation of Digital Seismograph Networks. https://doi.org/10.7914/SN/RF

Utrecht University (UU Netherlands) (1983) NARS. Dataset/Seismic Network. International Federation of Digital Seismograph Networks. https://doi.org/10.7914/SN/NR

ZAMG-Zentralanstalt für Meterologie und Geodynamik (1987) Austrian Seismic Network. Dataset/Seismic Network. International Federation of Digital Seismograph Networks. https://doi.org/10. 7914/SN/OE 